\title{
ChemComm
}

Check for updates

Cite this: Chem. Commun., 2019, 55,6102

Received 28th February 2019 Accepted 29th April 2019

DOI: $10.1039 / c 9 c c 01676 g$

rsc.li/chemcomm

\section{Synthesis of germanium nanocrystals from solid-state disproportionation of a chloride-derived germania glass $\dagger$}

\author{
Yujie Wang, (D) a Utkarsh Ramesh, ${ }^{a}$ Charles K. A. Nyamekye, ${ }^{\text {bc }}$ Bradley J. Ryan, ${ }^{a}$ \\ Rainie D. Nelson, (D) abdulla M. Alebri, ${ }^{a}$ Umar H. Hamdeh, ${ }^{a}$ Atefe Hadi, ${ }^{a}$ \\ Emily A. Smith (D) ${ }^{\text {bc }}$ and Matthew G. Panthani (D)*a
}

\begin{abstract}
Germanium nanocrystals (Ge NCs) have potential to be used in several optoelectronic applications such as photodetectors and light-emitting diodes. Here, we report a solid-state route to synthesizing Ge NCs through thermal disproportionation of a germania $\left(\mathrm{GeO}_{x}\right)$ glass, which was synthesized by hydrolyzing a $\mathrm{GeCl}_{2}$.dioxane complex. The $\mathrm{GeO}_{x}$ glass synthesized in this manner was found to have residual $\mathrm{Cl}$ content. The process of nanocrystal nucleation and growth was monitored using powder $\mathrm{X}$-ray diffraction, transmission electron microscopy, X-ray photoelectron spectroscopy and Raman spectroscopy. Compared to existing solid-state routes for synthesizing colloidal Ge NCs, this approach requires fewer steps and is amenable to scaling to large-scale reactions.
\end{abstract}

Quantum dots have tremendous potential for several optoelectronic applications due to their unique properties; ${ }^{1-3}$ however, many quantum dot materials contain toxic elements such as $\mathrm{Cd}$ and $\mathrm{Pb}$. This has motivated a search for other nanocrystal systems, including Group IV semiconductors ( $\mathrm{Si}, \mathrm{Ge}$, and Sn). ${ }^{4-6} \mathrm{Ge}$ NCs are thought to be promising for a variety of applications such as lightemitting diodes, ${ }^{7,8}$ nonvolatile memory, ${ }^{9}$ field-effect transistors, ${ }^{10}$ lithium ion batteries, ${ }^{11}$ and near-infrared photodetectors. ${ }^{12}$

Several synthetic methods for preparing Ge NCs have been reported, including solution-phase synthesis from Zintl salts, ${ }^{13,14}$ plasma-based synthesis, ${ }^{15}$ thermal processing of sol-gel derived from organogermanium, ${ }^{16-18}$ decomposition of organogermanes in supercritical fluids, ${ }^{19}$ microwave-assisted colloidal synthesis, ${ }^{20,21}$ and hot-injection based arrested precipitation. ${ }^{7,22}$ Very recently, there have been reports of solid state approaches using a $\mathrm{Ge}(\mathrm{OH})_{2}$ precursor. ${ }^{23-25}$ These approaches used $\mathrm{Ge}(\mathrm{OH})_{2}$ that was derived from $\mathrm{GeO}_{2}$, followed by thermal annealing to induce dehydration

\footnotetext{
${ }^{a}$ Department of Chemical and Biological Engineering, Iowa State University,

Ames, IA 50011, USA.E-mail: panthani@iastate.edu

${ }^{b}$ Department of Chemistry, Iowa State University, Ames, IA 50011, USA

${ }^{c}$ Ames Laboratory, U.S. Department of Energy, Ames, IA 50011, USA

$\dagger$ Electronic supplementary information (ESI) available: Experimental procedures, and characterization details. Additional XRD patterns, TEM images, XP, FTIR and Raman spectra. Table of Raman peak assignments and vibrational modes for the $\mathrm{GeCl}_{2}$.dioxane complex. See DOI: $10.1039 / \mathrm{c} 9 \mathrm{cc} 01676 \mathrm{~g}$
}

and disproportionation, ultimately resulting in Ge NCs suspended within a germania matrix.

In this report, we departed from this strategy by synthesizing $\mathrm{GeO}_{X}$ through the hydrolysis and subsequent dehydration of $\mathrm{GeCl}_{2}{ }^{26}{ }^{2}$ Compared to previous approaches, the $\mathrm{GeCl}_{2}$ precursor has the advantage of being hydrolyzed by water at room temperature to instantly form $\mathrm{Ge}(\mathrm{OH})_{2}$, which can subsequently be dehydrated to form $\mathrm{GeO}_{X}$. The $\mathrm{GeO}_{X}$ was subsequently used as a solid-state precursor for synthesizing Ge NCs by thermal disproportionation. Freestanding Ge NCs could be liberated by mixing the oxide-embedded Ge NCs with deionized water to selectively etch the matrix. Further surface modification could be achieved by first hydrogen terminating the Ge NC surfaces using a hydrofluoric acid (HF) solution followed by heating in the presence of a terminal alkene to induce hydrogermylation, which resulted in alkyl-terminated Ge NCs. In a typical reaction, $\mathrm{GeCl}_{2}$ - dioxane was hydrolyzed with water and dried under vacuum and heated to form a yellow powder that was subsequently annealed in $\mathrm{N}_{2}$ at elevated temperatures.

We use powder X-ray diffraction (XRD) to identify the processing temperature at which crystalline Ge begins to appear (Fig. 1). The $\mathrm{XRD}$ pattern of the hydrolyzed $\mathrm{GeCl}_{2}$-dioxane (prior to annealing) exhibits broad amorphous features centered around $31.4^{\circ}$ and $50.8^{\circ} 2 \theta$. Previous studies from Javadi $e t a l^{24,25}$ and Sun et al..$^{23}$ also reported amorphous features from $\mathrm{GeO}_{2}$-derived $\mathrm{GeO}$ prior to annealing; however these amorphous scattering features were at slightly lower angles $\left(27.5^{\circ}\right.$ and $\left.50^{\circ} 2 \theta\right)$ and were attributed to amorphous germanium. ${ }^{24,25}$ The different positions of the amorphous features in the precursors indicate that our samples may possess a different composition from the previous studies. Differential scanning calorimetry (DSC) reveals an exotherm that we hypothesized to coincide with the decomposition of the precursor and formation of Ge nuclei around $250{ }^{\circ} \mathrm{C}$ (Fig. S1, ESI $\dagger$ ). From XRD pattern, the precursor remains amorphous through dehydration at $250{ }^{\circ} \mathrm{C}$, and upon continued heating up to $325{ }^{\circ} \mathrm{C}$. Upon heating to $325{ }^{\circ} \mathrm{C}$, peaks corresponding to diamond cubic $\mathrm{Ge}$ and hexagonal $\mathrm{GeO}_{2}$ emerge. At higher temperatures, the relative intensities of cubic Ge reflections 


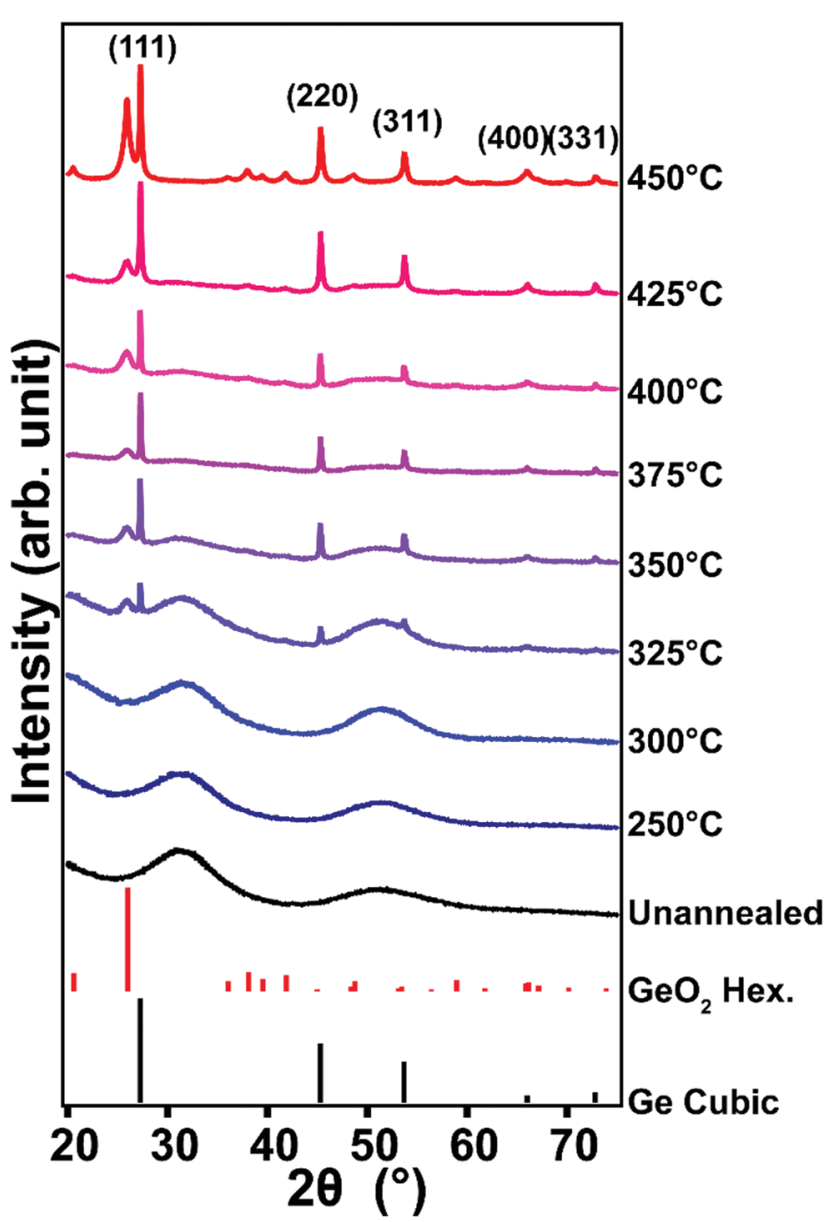

Fig. 1 XRD patterns of hydrolyzed $\mathrm{GeCl}_{2}$-dioxane before and after annealing at various temperatures. Cubic Ge reference: PDF \# 00-0040545, hexagonal $\mathrm{GeO}_{2}$ reference: PDF \# 00-036-1463.

increase relative to the features corresponding to the amorphous $\mathrm{GeO}_{X}$. There is relatively little signal indicating the presence of amorphous $\mathrm{GeO}_{X}$ for samples processed at temperatures greater than $400{ }^{\circ} \mathrm{C}$, suggesting that the $\mathrm{GeO}_{X}$ is mostly converted to crystalline $\mathrm{Ge}$ and $\mathrm{GeO}_{2}$. We note the products that are exposed to environments with relatively high humidity ( $\mathrm{RH} \geq 50 \%$ ) have reflections corresponding to hexagonal $\mathrm{GeO}_{2}$. However, samples that are prepared in low relative humidity $(\mathrm{RH} \leq 20 \%)$ do not show any reflections corresponding to crystalline $\mathrm{GeO}_{2}$ (Fig. S2, ESI $\dagger$ ), and rather only have broad amorphous features which we assign to amorphous $\mathrm{GeO}_{X}$, since these features have equivalent width and position to the hydrolyzed $\mathrm{GeCl}_{2}$-dioxane. These data suggest that the formation of crystalline $\mathrm{GeO}_{2}$ results from exposure to atmospheric moisture. This is in line with a previous experimental study demonstrating that water can cause the transformation of amorphous $\mathrm{GeO}_{2}$ to hexagonal crystalline $\mathrm{GeO}_{2}{ }^{27}$

Transmission electron microscopy (TEM) confirms the presence of Ge NCs at annealing temperatures at or above $325{ }^{\circ} \mathrm{C}$ (Fig. 2 and Fig. S3, ESI $\dagger$ ), with a measured $d$-spacing of $3.3 \AA$, consistent with the crystalline cubic Ge(111) plane. Particle size analysis of TEM images suggests that there is no trend in size with respect to

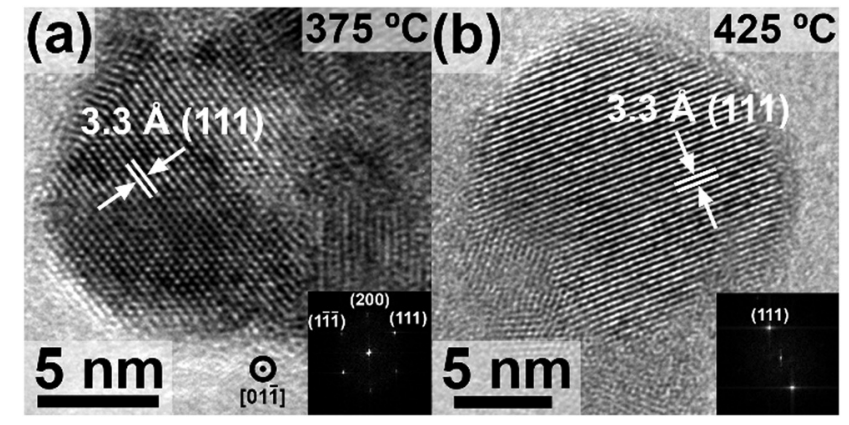

Fig. 2 TEM images of nanocrystals obtained from hydrolyzed $\mathrm{GeCl}_{2}$.dioxane annealed at (a) $375^{\circ} \mathrm{C}$ and (b) $425^{\circ} \mathrm{C}$. The insets show the corresponding FFT pattern indexed to diamond cubic Ge.

processing temperature. This is different from the observation of Javadi et al. of a clear increase in nanocrystal size with increasing annealing temperature. ${ }^{25}$ The Ge NCs are polydisperse and have different morphologies, which could be caused by the twostep heating procedure. ${ }^{5}$ The presence of unreacted precursors and amorphous species are also observed in the vicinity of Ge NCs, the presence of which decreases with increasing reaction temperature (Fig. S4-S9, ESI $\dagger$ ). This is consistent with XRD data that indicates the decrease of amorphous $\mathrm{GeO}_{X}$ with increasing processing temperature (Fig. 1).

X-ray photoelectron spectroscopy (XPS) measurements quantify the distribution of oxidation states of hydrolyzed $\mathrm{GeCl}_{2}$. dioxane before and after annealing at $250{ }^{\circ} \mathrm{C}$. The measurements suggest a disproportionation process occurs during thermal annealing (Fig. 3 and Fig. S12, ESI $\dagger$ ). As shown in Fig. S12 (ESI $\dagger$ ), prior to annealing, the hydrolyzed $\mathrm{GeCl}_{2}$. dioxane has signals from $\mathrm{Ge}, \mathrm{C}, \mathrm{O}$ as well as $\mathrm{Cl}$. The presence of $\mathrm{Cl}$ likely indicates incomplete conversion of $\mathrm{GeCl}_{2}$.dioxane to $\mathrm{Ge}(\mathrm{OH})_{2}$ during the hydrolysis step. High-resolution XPS (Fig. 3) of the hydrolyzed $\mathrm{GeCl}_{2}$-dioxane before annealing has Ge $3 \mathrm{~d}$ peak that is dominated by $\mathrm{Ge}^{2+}$, with smaller contributions from $\mathrm{Ge}^{4+}$ and $\mathrm{Ge}^{0.28}$ The $\mathrm{Ge}^{2+}$ signal is attributed to $\mathrm{Ge}(\mathrm{OH})_{2}$ from hydrolysis and unreacted $\mathrm{GeCl}_{2}$, while $\mathrm{Ge}^{4+}$ is attributed to surface oxidation. Due to the lack of crystalline features in XRD, the $\mathrm{Ge}^{0}$ signal likely arises from amorphous Ge from the precursor. After annealing at $250{ }^{\circ} \mathrm{C}$, the peak becomes broader and signals from $\mathrm{Ge}^{0}$ and $\mathrm{Ge}^{4+}$ increases while signal from $\mathrm{Ge}^{2+}$ decreases, suggesting that the disproportionation process begins at temperatures as low as $250{ }^{\circ} \mathrm{C}$, supporting the hypothesis that the exotherm in DSC $250{ }^{\circ} \mathrm{C}$ is related to the decomposition of the precursor and formation of Ge nuclei.

To better understand the formation of crystalline Ge at unprecedentedly low temperatures, we measured the Raman spectra of the $\mathrm{GeCl}_{2}$. dioxane precursor before and after hydrolysis (Fig. 4a). The peak of $\mathrm{GeCl}_{2}$. dioxane at $316 \mathrm{~cm}^{-1}$ is attributed to the Ge phonon mode of a Ge-Cl stretch, ${ }^{28}$ and the shoulder around $280 \mathrm{~cm}^{-1}$ is attributed to amorphous Ge. ${ }^{29,30}$ The entire Raman spectrum of $\mathrm{GeCl}_{2}$.dioxane from 200 to $4000 \mathrm{~cm}^{-1}$ is shown in Fig. S13 (ESI $\dagger$ ) and detailed Raman peak assignments are shown in Table $\mathrm{S} 1$ (ESI $\dagger$ ). After hydrolyzing the $\mathrm{GeCl}_{2}$. dioxane, the $\mathrm{Ge}-\mathrm{Cl}$ stretch becomes relatively weak compared to the amorphous Ge signal, but is still present (Fig. 4a). This is 

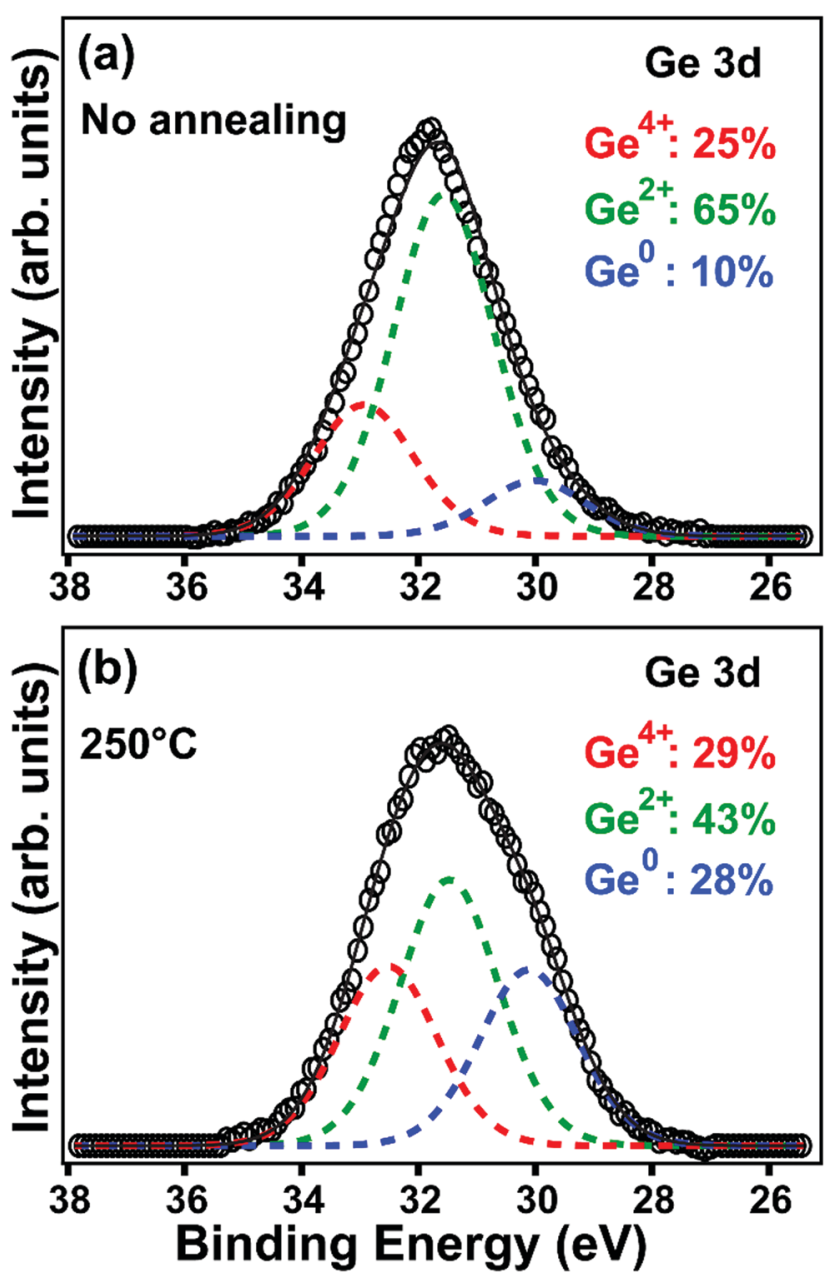

Fig. 3 XPS of hydrolyzed $\mathrm{GeCl}_{2}$. dioxane (a) before annealing, and (b) after annealing at $250{ }^{\circ} \mathrm{C}$. Collected data are shown with open circles. Fitted data are shown in solid curve of black ( $\mathrm{Ge} 3 \mathrm{~d})$, dash curves red $\left(\mathrm{Ge}^{4+}\right)$, green $\left(\mathrm{Ge}^{2+}\right)$, and blue $\left(\mathrm{Ge}^{0}\right)$.

consistent with the $\mathrm{Cl}$ signal seen in XPS and confirms the presence of $\mathrm{GeCl}_{2}$ before annealing (Fig. S12, ESI $\dagger$ ). Furthermore, a new Raman peak associated with an $\mathrm{O}-\mathrm{H}$ bond at $3510 \mathrm{~cm}^{-1}$ appears after hydrolysis (as shown in Fig. S14, ESI $\dagger$ ), indicating that some of the $\mathrm{GeCl}_{2}$ reacted with water to form $\mathrm{Ge}(\mathrm{OH})_{2}$. The presence of the peak associated with amorphous Ge is consistent with the XPS spectra that has photoemission from $\mathrm{Ge}^{0}$ in the hydrolyzed $\mathrm{GeCl}_{2}$-dioxane (Fig. 3).

After thermally annealing the hydrolyzed precursor at temperatures greater than or equal to $250{ }^{\circ} \mathrm{C}$, peaks corresponding to $\mathrm{Ge}-\mathrm{Ge}$ begin to appear, with Raman shift of around $285 \mathrm{~cm}^{-1}$ (Fig. $4 \mathrm{~b}$ ). This presumably indicates the formation of small Ge NCs or possibly nuclei at temperatures as low as $250{ }^{\circ} \mathrm{C}$, consistent with observation of exotherm in DSC and the $\mathrm{Ge}^{0}$ from XPS at $250{ }^{\circ} \mathrm{C}$. As shown in Fig. 4b, the Raman peaks become more symmetric, sharper, and shift to higher wavenumbers with increasing processing temperatures (see Fig. S15 for more details, ESI $\dagger$ ). Qualitatively, the change in peak shape indicates that the size of the Ge NCs increases with temperature, as is predicted by the phonon confinement model. ${ }^{30-32}$

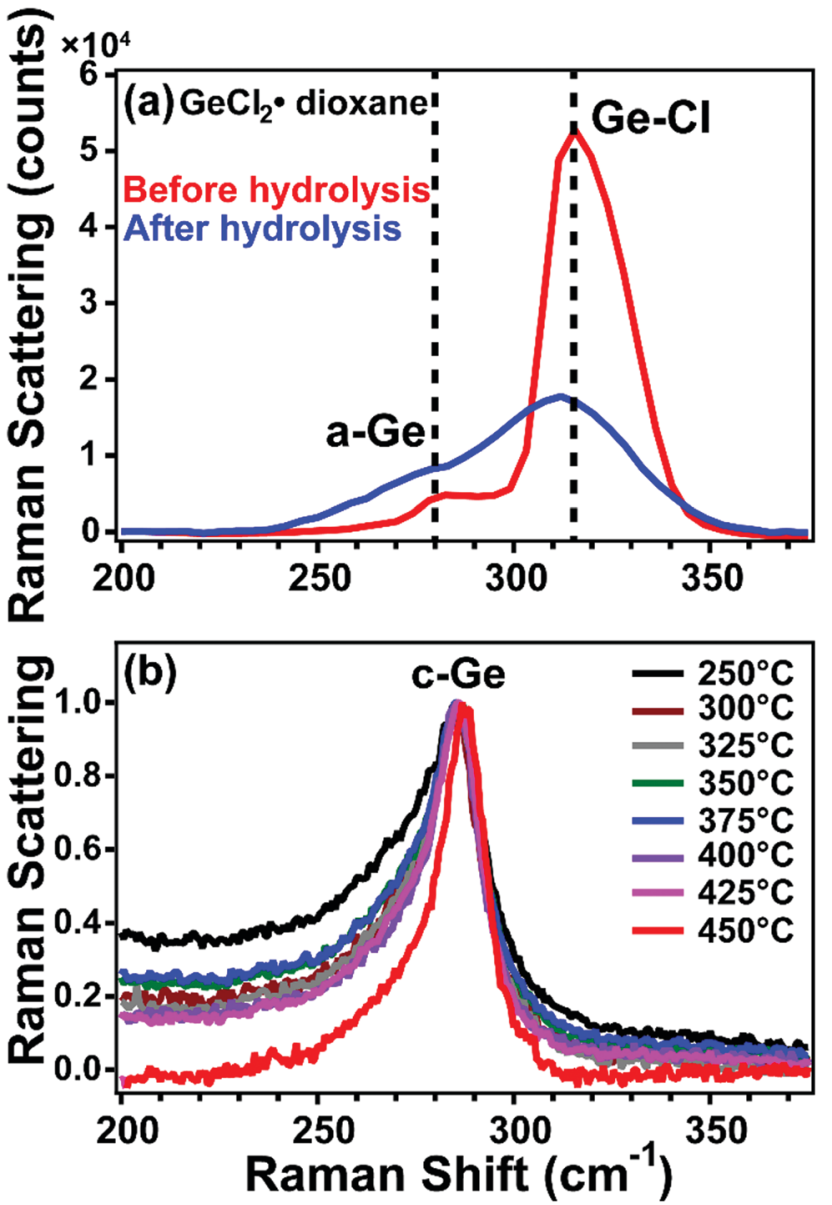

Fig. 4 (a) Baseline-corrected Raman spectra of $\mathrm{GeCl}_{2}$.dioxane precursor before hydrolysis (red) and after hydrolysis (blue). (b) Normalized Raman spectra of hydrolyzed $\mathrm{GeCl}_{2}$. dioxane annealed at temperatures between 250 and $450^{\circ} \mathrm{C}$.

Compared to previous reports of Ge NC synthesis from oxide disproportionation, the approach reported here results in the formation of crystalline Ge at relatively low temperatures. ${ }^{18,23,24,33}$ While further work must be done to compare the crystallization dynamics between these approaches, there are some hints as to what could cause the different crystallization temperature. As previously mentioned, the XRD pattern of the hydrolyzed product has different amorphous feature locations from previous reports. ${ }^{18,23,24,33}$ Also, Raman and XPS results imply the presence of $\mathrm{Ge}-\mathrm{Cl}$ bonds (see Fig. S12 (ESI $\dagger$ ) for the survey XP spectrum of hydrolyzed $\mathrm{GeCl}_{2}$.dioxane). $\mathrm{Ge}-\mathrm{Cl}$ bonds have a lower dissociation energy than Ge-O $\left(390.8 \pm 9.6 \mathrm{~kJ} \mathrm{~mol}^{-1}\right.$ and $652.7 \pm 8.4 \mathrm{~kJ} \mathrm{~mol}^{-1}$, respectively), suggesting $\mathrm{Ge}-\mathrm{Cl}$ bonds can dissociate at a lower temperature than Ge-O bonds. ${ }^{34}$ We speculate that this could contribute to the formation of Ge NCs at lower temperatures.

The Ge NCs are functionalized using hydrogermylation. Briefly, the annealed $\mathrm{GeO}_{X}$ glass is etched with warm water to dissolve $\mathrm{GeO}_{2}$ and liberate freestanding Ge NCs, which are then dispersed in $\mathrm{HF}$ acid to terminate Ge NCs with hydrogen atoms. $^{23,24}$ Finally, the H-terminated Ge NCs are dispersed in 1-octadecene and heated to $200{ }^{\circ} \mathrm{C}$ in an inert atmosphere to 
initiate hydrogermylation, terminating the Ge NC surfaces with 1-octadecene. TEM images of the passivated sample suggest that the $\mathrm{GeO}_{2}$ and precursors are removed (Fig. S16, ESI $\dagger$ ). The main lattice spacing in selected area electron diffraction (3.3, 2.0, and $1.7 \AA$ ) corresponds to crystalline Ge, confirming the presence of Ge NCs. Fourier transform infrared spectroscopy shows the presence of $\mathrm{Ge}-\mathrm{C}$ stretching mode, indicating the success of surface passivation (Fig. S17, ESI $\dagger$ ).

We attempted to measure photoluminescence (PL) from the hydrogen-terminated and 1-octadecene-terminated samples; however, no PL is detected in any sample. The absence of PL could arise from surface defects, dangling bonds from etching, impurities, or surface species that are not adequately removed during the etching process. The absence of PL is also reported for Ge NCs obtained using similar oxide-based solid-state synthesis. $^{24}$

In conclusion, we report the synthesis of Ge NCs using solidstate disproportionation of a chloride-derived $\mathrm{GeO}_{X}$ glass. XRD and TEM results showed the presence of crystalline Ge particles at processing temperature as low as $325{ }^{\circ} \mathrm{C}$. TEM results also indicated the nanocrystals were highly polydisperse with irregular morphologies. XPS and Raman spectra provided insights into the mechanism by which the NCs were formed, with residual $\mathrm{Cl}$ present in the $\mathrm{GeO}_{X}$ precursor and Ge with short-range order being formed at temperatures as low as $250{ }^{\circ} \mathrm{C}$. XRD data indicated the $\mathrm{GeO}_{X}$ precursor had amorphous features that were shifted to a higher $2 \theta$ compared to prior reports. The Ge NCs obtained with this method could be surface-passivated with an organic ligand using hydrogermylation. Compared to other methods for creating Ge NCs, this method takes relatively little time and does not require the use of strong acids or highly exothermic reactions and thus has potential for being scaled up easily, providing a promising route for large-scale synthesis of Ge NCs for various applications. However, better control over size and morphology would be desirable for many applications.

This work was supported by the Air Force Office of Scientific Research Young Investigator Program under grant number FA9550-17-1-0170. MGP acknowledges support from the Herbert L. Stiles faculty fellowship. RDN and BJR acknowledge support from the NSF Graduate Research Fellowship Program (DGE1744592). Support for the Raman spectroscopy measurements was provided by the U.S. Department of Energy, Office of Science, Basic Energy Sciences, Chemical Sciences, Geosciences, and Biosciences Division. The Raman spectroscopy research was performed at the Ames Laboratory, which is operated for the U.S. DOE by Iowa State University under contract \# DE-AC02-07CH11358.

\section{Conflicts of interest}

There are no conflicts to declare.

\section{Notes and references}

1 M. L. Steigerwald, A. P. Alivisatos, J. M. Gibson, T. D. Harris, R. Kortan, A. J. Muller, A. M. Thayer, T. M. Duncan, D. C. Douglass and L. E. Brus, J. Am. Chem. Soc., 1988, 110, 3046-3050.

2 A. Mews, A. V. Kadavanich, U. Banin and A. P. Alivisatos, Phys. Rev. B: Condens. Matter Mater. Phys., 1996, 53, R13242.

3 A. Cao, Z. Liu, S. Chu, M. Wu, Z. Ye, Z. Cai, Y. Chang, S. Wang, Q. Gong and Y. Liu, Adv. Mater., 2010, 22, 103-106.

4 C. M. Hessel, D. Reid, M. G. Panthani, M. R. Rasch, B. W. Goodfellow, J. Wei, H. Fujii, V. Akhavan and B. A. Korgel, Chem. Mater., 2012, 24, 393-401.

5 W. Sun, C. Qian, X. S. Cui, L. Wang, M. Wei, G. Casillas, A. S. Helmy and G. A. Ozin, Nanoscale, 2016, 8, 3678-3684.

6 M. Dasog, G. B. De los Reyes, L. V. Titova, F. A. Hegmann and J. G. C. Veinot, ACS Nano, 2014, 8, 9636-9648.

7 D. C. Lee, J. M. Pietryga, I. Robel, D. J. Werder, R. D. Schaller and V. I. Klimov, J. Am. Chem. Soc., 2009, 131, 3436-3437.

8 D. A. Ruddy, J. C. Johnson, E. R. Smith and N. R. Neale, ACS Nano, 2010, 4, 7459-7466.

9 M. Kanoun, C. Busseret, A. Poncet, A. Souifi, T. Baron and E. Gautier, Solid-State Electron., 2006, 50, 1310-1314.

10 Z. C. Holman, C.-Y. Liu and U. R. Kortshagen, Nano Lett., 2010, 10, 2661-2666.

11 Y. J. Cho, H. S. Im, H. S. Kim, Y. Myung, S. H. Back, Y. R. Lim, C. S. Jung, D. M. Jang, J. Park, E. H. Cha, W. I. Cho, F. Shojaei and H. S. Kang, ACS Nano, 2013, 7, 9075-9084.

12 X. Ma, B. Yuan and Z. Yan, Opt. Commun., 2006, 260, 337-339.

13 B. R. Taylor, S. M. Kauzlarich, H. W. H. Lee and G. R. Delgado, Chem. Mater., 1998, 10, 22-24.

14 X. Ma, F. Wu and S. M. Kauzlarich, J. Solid State Chem., 2008, 181, $1628-1633$.

15 R. Gresback, Z. Holman and U. Kortshagen, Appl. Phys. Lett., 2007, 91, 093119.

16 E. J. Henderson, M. Seino, D. P. Puzzo and G. A. Ozin, ACS Nano, 2010, 4, 7683-7691.

17 M. Hoffman and J. G. C. Veinot, Chem. Mater., 2012, 24, 1283-1291.

18 E. J. Henderson, C. M. Hessel and J. G. C. Veinot, J. Am. Chem. Soc., 2008, 130, 3624-3632.

19 X. Lu, K. J. Ziegler, A. Ghezelbash, K. P. Johnston and B. A. Korgel, Nano Lett., 2004, 4, 969-974.

20 A. Bernard, K. Zhang, D. Larson, K. Tabatabaei and S. M. Kauzlarich, Inorg. Chem., 2018, 57, 5299-5306.

21 E. Muthuswamy, A. S. Iskandar, M. M. Amador and S. M. Kauzlarich, Chem. Mater., 2013, 25, 1416-1422.

22 X. Lu, B. A. Korgel and K. P. Johnston, Chem. Mater., 2005, 17, 6479-6485.

23 W. Sun, G. Zhong, C. Kübel, A. A. Jelle, C. Qian, L. Wang, M. Ebrahimi, L. M. Reyes, A. S. Helmy and G. A. Ozin, Angew. Chem., 2017, 129, 6426-6431.

24 M. Javadi, D. Picard, R. Sinelnikov, M. A. Narreto, F. A. Hegmann and J. G. C. Veinot, Langmuir, 2017, 33, 8757-8765.

25 M. Javadi, V. K. Michaelis and J. G. C. Veinot, J. Phys. Chem. C, 2018, 122, 17518-17525.

26 N. N. Greenwood and A. Earnshaw, Chemistry of the Elements, Elsevier, 2012.

27 Z. Xiao, X. Sun, X. Li, Y. Wang, Z. Wang, B. Zhang, X. L. Li, Z. Shen, L. B. Kong and Y. Huang, Nano Lett., 2018, 18, 3290-3296.

28 G. A. Ozin and A. V. Voet, J. Chem. Phys., 1972, 56, 4768-4775.

29 D. Bermejo and M. Cardona, J. Non-Cryst. Solids, 1979, 32, 405-419.

30 M. Fujii, S. Hayashi and K. Yamamoto, Jpn. J. Appl. Phys., 1991, 30, 687. 31 I. H. Campbell and P. M. Fauchet, Solid State Commun., 1986, 58, 739-741.

32 A. K. Arora, M. Rajalakshmi, T. R. Ravindran and V. Sivasubramanian, J. Raman Spectrosc., 2007, 38, 604-617.

33 A. Schacht, C. Sternemann, A. Hohl, H. Sternemann, C. J. Sahle, M. Paulus and M. Tolan, J. Non-Cryst. Solids, 2009, 355, 1285-1287.

34 Y.-R. Luo, Comprehensive Handbook of Chemical Bond Energies, CRC Press, 2007. 